\title{
Complete Genomic Data of Burkholderia glumae Strain GX Associated with Bacterial Panicle Blight of Rice in China
}

Sai Wang, Wenhan Nie, Qiang Gong, Yaohui Lee, Hanxia Shui, Gongyou Chen, and Bo Zhu ${ }^{\dagger}$

School of Agriculture and Biology, Shanghai Jiao Tong University/Key Laboratory of Urban Agriculture by Ministry of Agriculture of China, Shanghai 200240, China

\begin{abstract}
Burkholderia glumae is a seedborne pathogen causing bacterial panicle blight of rice. Here, we report the complete genome of $B$. glumae strain GX, which represents the first wholegenome sequence of an isolate from China. The assembled genome consisted of five contigs, with two circular chromosomes of 3,712,850 and 2,750,046 bp and three plasmids of 201,571, 105,587 , and $96,100 \mathrm{bp}$. This complete genome will provide a valuable resource for further studies on bacterial panicle blight worldwide.
\end{abstract}

\section{Genome Announcement}

Burkholderia glumae is a gram-negative, seedborne rice pathogen responsible for causing bacterial panicle blight (BPB), also known as bacterial grain rot. BPB was first described in Japan in the 1950s. It has caused significant reductions in the rice yield in many rice-growing countries (Cui et al. 2016). Considering the optimal temperature range for the growth of $B$. glumae $\left(30\right.$ to $35^{\circ} \mathrm{C}$ ), the environmental conditions prevalent during the ricegrowing season, and global climate change, it is believed that this disease will occur more frequently (Ham et al. 2011). A growing body of evidence shows that phytotoxins and lipases are the major pathogenic determinants of $B$. glumae. Two polycistronic operons, tox $A B C D E$ and toxFGHI, are responsible for the toxoflavin biosynthesis pathway and toxoflavin transport, respectively (Kim et al. 2004; Suzuki et al. 2004). The expression of both of these operons requires a transcriptional activator, ToxJ, which is regulated by quorum sensing (QS). LipA is the most important lipase related to virulence, and it is also dependent on the QS system (Devescovi et al. 2007). In 2004, BPB was first reported in Heilongjiang Province, China. B. glumae was listed in the "Entry Plant Quarantine Pest List" of the People's Republic of China in 2007. However, the complete genome sequences of $B$. glumae strains isolated from China remain to be determined and the genomic difference between Chinese isolates and other strains are still unclear. Thus, in this study, we report the complete whole-genome sequence of the first Chinese B. glumae strain, GX.

B. glumae strain GX was isolated from diseased rice seed, obtained from Guangxi Province, China, in 2009. Genomic DNA of B. glumae was extracted using the AxyPrep Bacterial Genomic DNA Miniprep Kit (Axygen). A ligation sequencing kit (SQK-LSK109) was used, with $1 \mu \mathrm{g}$ of DNA, to prepare the sequencing library for Nanopore sequencing. The library was loaded onto an R9.4 flow cell and sequenced using a MinION device, with the default basecalling integrated in MinKNOW v3.1.13 software. In total, 53,338 reads were

\footnotetext{
${ }^{\dagger}$ Corresponding author: B. Zhu; bzhu1981@ sjtu.edu.cn
}

*The $e$-Xtra logo stands for "electronic extra" and indicates that one supplementary figure is published online.

The author(s) declare no conflict of interest.

Accepted for publication 29 January 2020.

$e-X$ tra $^{*}$

Funding

This work was supported by the National Key R\&D Program of China (2018YFD0201202 and 2017YFD0201108), the Zhejiang National Natural Science Foundation of China (LY17C010006), the Agri-X Interdisciplinary Fund of Shanghai Jiao Tong University (Agri-X2017010), the State Key Laboratory for Biology of Plant Diseases and Insect Pests (SKLOF201802), and the Open Project Program of State Key Laboratory of Rice Biology (20190109).

\section{Keywords}

Burkholderia glumae, Pacbio, toxoflavin 
Table 1. Genome comparison between Burkholderia glumae GX and BGR1

\begin{tabular}{|c|c|c|c|c|c|c|}
\hline Genomic status & Strain & Accession & Size (bp) & ANI (\%) & GC (\%) & $\begin{array}{l}\text { Coding sequences } \\
\text { (with protein) }\end{array}$ \\
\hline Chromosome 1 & $\begin{array}{l}\text { GX } \\
\text { BGR1 }\end{array}$ & $\begin{array}{l}\text { CP045087.1 } \\
\text { CP001503 }\end{array}$ & $\begin{array}{l}3,712,850 \\
3,906,507\end{array}$ & 99.63 & $\begin{array}{l}68.1 \\
68.11\end{array}$ & $\begin{array}{l}3,210 \\
3,544\end{array}$ \\
\hline Chromosome 2 & $\begin{array}{l}\text { GX } \\
\text { BGR1 }\end{array}$ & $\begin{array}{l}\text { CP045089.1 } \\
\text { CP001504.2 }\end{array}$ & $\begin{array}{l}2,750,046 \\
2,827,333\end{array}$ & 99.63 & $\begin{array}{l}68.99 \\
68.77\end{array}$ & $\begin{array}{l}2,117 \\
2,202\end{array}$ \\
\hline Plasmid 1 & $\begin{array}{l}\text { GX } \\
\text { BGR1 }\end{array}$ & $\begin{array}{l}\text { CP045090.1 } \\
\text { CP001505.1 }\end{array}$ & $\begin{array}{l}201,571 \\
133,591\end{array}$ & $\begin{array}{l}99.59 \\
\ldots\end{array}$ & $\begin{array}{l}61.42 \\
60.59\end{array}$ & $\begin{array}{l}152 \\
114\end{array}$ \\
\hline Plasmid 2 & $\begin{array}{l}\text { GX } \\
\text { BGR1 }\end{array}$ & $\begin{array}{l}\text { CP045091.1 } \\
\text { CP001506.1 }\end{array}$ & $\begin{array}{l}105,587 \\
282,889\end{array}$ & $\begin{array}{l}96.92 \\
\ldots\end{array}$ & $\begin{array}{l}62.12 \\
62.94\end{array}$ & $\begin{array}{r}96 \\
106\end{array}$ \\
\hline Plasmid 3 & $\begin{array}{l}\text { GX } \\
\text { BGR1 }\end{array}$ & $\begin{array}{l}\text { CP045092.1 } \\
\text { CP001507.1 }\end{array}$ & $\begin{array}{r}96,100 \\
141,067\end{array}$ & $\begin{array}{l}97.25 \\
\ldots\end{array}$ & $\begin{array}{l}64.28 \\
62.68\end{array}$ & $\begin{array}{r}75 \\
119\end{array}$ \\
\hline $\begin{array}{l}\text { Plasmid } 4 \\
\text { Sum }\end{array}$ & $\begin{array}{l}\text { BGR1 } \\
\text { GX } \\
\text { BGR1 }\end{array}$ & $\begin{array}{l}\text { CP001508.1 } \\
\ldots \\
\ldots\end{array}$ & $\begin{array}{r}134,346 \\
6,866,154 \\
7,284,636\end{array}$ & $\begin{array}{l}\ldots \\
99.62 \\
\ldots\end{array}$ & $\begin{array}{l}62.71 \\
68.12 \\
67.93\end{array}$ & $\begin{array}{r}117 \\
5,650 \\
6,202\end{array}$ \\
\hline
\end{tabular}

obtained after sequencing, with an $\mathrm{N}_{50}$ value of 25,729 bp and average read length of $20,410 \mathrm{bp}$, consisting of $1,088,656,593$ bases in total. After quality control, an assembly of contigs from the subreads was generated using Canu 1.8 (Koren et al. 2017), and Pilon was used for improving the genome assembly (Walker et al. 2014). Finally, chromosomes and plasmids were circularized using Circlator 1.5.5 (Hunt et al. 2015). Annotation of each contig was performed using the NCBI Prokaryotic Genome Annotation Pipeline (Tatusova et al. 2016). Toxoflavin genes were detected and annotated using antiSMASH 5.0 (Blin et al. 2019), while the average nucleotide identity (ANI) between the GX and BGR1 strains was calculated using Pyani (Pritchard et al. 2016).

The genome of $B$. glumae strain GX was found to be composed of two unique circular chromosomes and three unique circular plasmids (Table 1). This is similar to the genome of B. glumae strain BGR1, which is composed of two circular chromosomes and four circular plasmids (Lim et al. 2009). All ANI scores were greater than 95\%, suggesting that GX and BGR1 belong to the same species. Chromosome 1 was 3,712,850 bp long, with $68.10 \% \mathrm{GC}$ content, and was predicted to include 3,210 protein-encoding genes. The sequencing coverage of chromosome 1 was 137. Chromosome 2 was 2,750,046 bp long, with $68.99 \%$ GC content, predicted to include 2,117 protein-encoding genes. The sequencing coverage of chromosome 2 was 144. Plasmids 1,2 , and 3 consisted of $201,571,105,587$, and $96,100 \mathrm{bp}$, respectively (Table 1). These plasmids were predicted to include 152, 96, and 75 protein-encoding genes, respectively. The total genome size of $B$. glumae strain GX was $6,866,154$ bp, including 5,650 protein-encoding genes. The circular representation of the complete genome of $B$. glumae strain GX is shown in Supplementary Figure S1. Overall, This complete genome will provide a valuable resource for further studies on bacterial panicle blight in China and worldwide.

Data availability. The whole-genome sequences reported here have been deposited in DNA Data Bank of Japan/European Nucleotide Archive/GenBank, under the accession numbers CP045087 for chromosome 1, CP045088 for chromosome 2, CP045089 for plasmid 1, CP045090 for plasmid 2, and CP045091 for plasmid 3. The versions described in this article are the first versions.

\section{Acknowledgments}

We thank S. Huang for providing the GX strain for this study.

\section{Literature Cited}

Blin, K., Shaw, S., Steinke, K., Villebro, R., Ziemert, N., Lee, S. Y., Medema, M. H., and Weber, T. 2019. antiSMASH 5.0: Updates to the secondary metabolite genome mining pipeline. Nucleic Acids Res. 47:W81-W87.

Cui, Z., Ojaghian, M. R., Tao, Z., Kakar, K. U., Zeng, J., Zhao, W., Duan, Y., Vera Cruz, C. M., Li, B., Zhu, B., and Xie, G. 2016. Multiplex PCR assay for simultaneous detection of six major bacterial pathogens of rice. J. Appl. Microbiol. 120:1357-1367.

Devescovi, G., Bigirimana, J., Degrassi, G., Cabrio, L., LiPuma, J. J., Kim, J., Hwang, I., and Venturi, V. 2007. Involvement of a quorum-sensing-regulated lipase secreted by a clinical isolate of Burkholderia glumae in severe disease symptoms in rice. Appl. Environ. Microbiol. 73:4950-4958.
Ham, J. H., Melanson, R. A., and Rush, M. C. 2011. Burkholderia glumae: Next major pathogen of rice? Mol. Plant Pathol. 12:329-339.

Hunt, M., De Silva, N., Otto, T. D., Parkhill, J., Keane, J. A., and Harris, S. R. 2015. Circlator: Automated circularization of genome assemblies using long sequencing reads. Genome Biol. 16:294.

Kim, J., Kim, J. G., Kang, Y., Jang, J. Y., Jog, G. J., Lim, J. Y., Kim, S., Suga, H., Nagamatsu, T., and Hwang, I. 2004. Quorum sensing and the LysR-type transcriptional activator ToxR regulate toxoflavin biosynthesis and transport in Burkholderia glumae. Mol. Microbiol. 54:921-934.

Koren, S., Walenz, B. P., Berlin, K., Miller, J. R., Bergman, N. H., and Phillippy, A. M. 2017. Canu: Scalable and accurate long-read assembly via adaptive k-mer weighting and repeat separation. Genome Res. 27:722-736. 
Lim, J., Lee, T. H., Nahm, B. H., Do Choi, Y., Kim, M., and Hwang, I. 2009. Complete genome sequence of Burkholderia glumae BGR1. J. Bacteriol. 191:3758-3759.

Pritchard, L., Glover, R. H., Humphris, S., Elphinstone, J. G., and Toth, I. K. 2016. Genomics and taxonomy in diagnostics for food security: Soft-rotting enterobacterial plant pathogens. Anal. Methods 8:12-24.

Suzuki, F., Sawada, H., Azegami, K., and Tsuchiya, K. 2004. Molecular characterization of the tox operon involved in toxoflavin biosynthesis of Burkholderia glumae. J. Gen. Plant Pathol. 70:97-107.
Tatusova, T., DiCuccio, M., Badretdin, A., Chetvernin, V., Nawrocki, E. P., Zaslavsky, L., Lomsadze, A., Pruitt, K. D., Borodovsky, M., and Ostell, J. 2016. NCB prokaryotic genome annotation pipeline. Nucleic Acids Res. 44:6614-6624. doi: 10.1093/nar/gkw569

Walker, B. J., Abeel, T., Shea, T., Priest, M., Abouelliel, A., Sakthikumar, S., Cuomo, C. A., Zeng, Q., Wortman, J., Young, S. K., and Earl, A. M. 2014. Pilon: An integrated tool for comprehensive microbial variant detection and genome assembly improvement. PLoS One 9:e112963. 